\title{
Sport and Physical Education at Abdelmalek Essaâdi University: State of the Art
}

\author{
Soulaiman HARFOUF \\ Interdisciplinary Research Laboratory on Pedagogical Engineering \\ Higher School of Education-Abdelmalek Essaâdi University (UAE), Tetouan, Morocco
}

\begin{abstract}
This research deals with the issue of Physical Education (PE) and Sport at Abdelmalek Essaâdi University, Tetouan, Morrocco. It adopts a problem related to the diagnosis and development of the Physical Education/sport system in this Moroccan institution of public higher education. After verifying whether certain factors are responsible for the dysfunction of this system at the UAE, this study subsequently makes proposals that could contribute to improving its performance. The results of this study show that the PE/sport system in the UAE suffers from a more or less significant lack, in number and quality, of human, financial, material and infrastructural resources. On the other hand, a deficient and non-functional organization, the absence of management strategies, the omission of regular evaluation of the system, the low motivation and the lack of commitment of the administrative and associative actors mark the managerial approach of the sports sector in the majority of schools and faculties of the UAE. Consequently, we conclude that all of these elements are responsible for the dysfunctional situation that $\mathrm{PE}$ and sport are currently experiencing in the UAE. Also, the conclusions of this study reveal the way in which the leaders in this university represent the importance of sport activities among the educational, academic and para-academic offer. All of them are in favor of developing sports in their institutions, but without being really determined and equipped to make it happen.
\end{abstract}

Keywords: UAE University, State of the art, University sport, Physical Education.

\section{INTRODUCTION}

In Morocco, Physical Education (PE) and University Sport (US) are two essential components of the national sport [1]. In addition to their participation in the overall training of students, they help in the early detection of promising sports talents [2]. However, and for at least twenty years, it is not so difficult to agree that the couple sport/physical education in Moroccan universities lives a chronic crisis situation that can be identified at several levels.

This study attempts to explore the current situation of the PE/UMS system in the institutions of the Abdelmalek Essaâdi University-Tetouan (UAE). It proposes to verify whether some sources of dysfunction in national sport (civil and university) are also for sport at the UAE. It then plans to make proposals likely to contribute to its upgrading and improving its performance [3].

\section{Problematics}

First, confirm that you have the correct template for your paper size. This template has been tailored for output on the $21 \mathrm{~cm} \mathrm{X} 28 \mathrm{~cm}$ Paper Size. It has been established that national sport suffers from inadequacies and deficiencies in terms of infrastructure and equipment, financial resources, management and governance [4].
The two questions we ask are first to verify to what extent the factors related to infrastructure, governance and financial and human means responsible for the fragile situation of national sport, are they also responsible for sport in UAE-Tetouan? In other words, do these elements represent real causes of the degradation of the sport/EPS system in the University of Tetouan?

Furthermore, attempting to positivize these indicators involves considering them in the particular context of the UAE. Consequently, we explore the measures to be taken to qualitatively and quantitatively improve the performance of the sport/school system at the UAE. These are the two main questions we will attempt to answer.

\section{MeTHODOLOGY}

In order to carry out the inventory of the sports system in this university and to identify the opportunities to be seized to improve it, a system of data collection and analysis was used. Interview guides, inventory grids and documentary analysis sheets were designed. A field survey was conducted with thirty-eight (38) interviewees among decision makers, actors and beneficiaries of sports services of the UAE, its institutions and the two university halls of residence in Tangier-Tetouan region. Seventeen (17) reports of different contents were also subject to an in-depth and guided examination. 


\section{RESUlts AND Discussion}

\section{A. Insufficient material resources Insufficient}

Sport in the UAE is experiencing an acute deficit in human, material and financial resources.

\section{1) Old and insufficient sports infrastructure.}

The practice of sports requires infrastructure and equipment that meet safety and performance standards. These conditions are lacking in the UAE. In addition, there are problems related to material and human resources. Indeed, almost all of the interviewees (87\%) consider the sports infrastructure available at the university in question does not allow for rigorous, varied and continuous programming of physical and sports activities. Directors and deans, people in charge of sports and students agree on this reality. They affirm that the sports spaces fitted out and equipped (fields and tracks of play, changing rooms, lighting and others) remain insufficient in number and quality to answer the number, in continuous growth, of the students of the UAE on the one hand, and to carry out the sports objectives which could be fixed on the other hand.

The Abdelmalek Essaâdi University which should have had a sporting influence thanks on its 36163 students finally has only a few sports grounds:

TABLE I. OVERALL USABLE SPORTS AREA BROKEN DOWN BY SPORTS ACTIVITIES.

\begin{tabular}{|c|c|c|}
\hline Nature & Number & Surface $\mathbf{m}^{2}$ \\
\hline Volleyball court & 07 & 1134 \\
\hline Handball court & 05 & 4000 \\
\hline Football court & 01 & 4050 \\
\hline Basketball court & 06 & 2520 \\
\hline Track and Field (TF) & 00 & 00 \\
\hline Sports hall (SH) & 01 & 800 \\
\hline
\end{tabular}

It appears from this table and the results of our interviews that the UAE has only a small amount of land dedicated to sports activities. Considering the number of students enrolled in this university, each student has only $0.37 \mathrm{~m}^{2}$ of space to practice sports, compared to $2.8 \mathrm{~m}^{2}$ in Tunisia for example [5].

The results also show that most of the sports facilities available at the University do not meet safety requirements; holes in the fields, undeveloped edges of the fields, lack of marking of playing surfaces, worn out goals and signs etc. are examples of this reality.

Similarly, the results obtained show that the distribution of existing sports facilities is unbalanced and does not allow all the institutions of the UAE to benefit more or less equally from the same opportunities to program sports teaching and animation activities.
TABLE II. TOTAL NUMBER OF ATHLETIC SPACES DISTRIBUTED BY UNIVERSITY INSTITUTION.

\begin{tabular}{|l|c|c|c|c|c|c|c|}
\cline { 2 - 8 } \multicolumn{1}{c|}{} & VB & FB & BB & HB & TF & SH & Total \\
\hline ENS & 1 & 0 & 1 & 1 & 0 & 0 & 03 \\
\hline FLSH & 1 & 0 & 1 & 1 & 0 & 0 & 03 \\
\hline FPT & 0 & 0 & 0 & 0 & 0 & 0 & 00 \\
\hline FS & 1 & 0 & 1 & 1 & 0 & 0 & 03 \\
\hline ENSAT & 0 & 0 & 0 & 0 & 0 & 0 & 00 \\
\hline FST & 1 & 0 & 0 & 0 & 0 & 1 & 02 \\
\hline ENSAT & 1 & 0 & 0 & 0 & 0 & 0 & 01 \\
\hline ENCG & 1 & 0 & 1 & 1 & 0 & 0 & 03 \\
\hline FSJES & 0 & 0 & 0 & 0 & 0 & 0 & 00 \\
\hline ISRFT & 1 & 0 & 1 & 0 & 0 & 0 & 02 \\
\hline FPL & 0 & 0 & 0 & 0 & 0 & 0 & 00 \\
\hline CUTE & 0 & 0 & 1 & 1 & 0 & 0 & 02 \\
\hline CUTA & 0 & 0 & 0 & 0 & 0 & 0 & 00 \\
\hline TOTAL & $\mathbf{7}$ & $\mathbf{0}$ & $\mathbf{6}$ & $\mathbf{5}$ & $\mathbf{0}$ & $\mathbf{1}$ & $\mathbf{1 9}$ \\
\hline
\end{tabular}

We emphasize here essentially the total absence of any sports space, equipped or not, in five (5) of the thirteen (13) institutions. This state of affairs further complicates the task of those in charge of these institutions to respond to the sports demands of certain students and teachers.

In a similar vein, those in charge of sports in the different institutions of the UAE as well as a good number of students believe that the sports infrastructures, currently available, can only timidly respond to the multiple and varied sports demands of students. The sports offer does not cover the field of social practices of reference and consequently remains below the expectations of young people: absence of swimming pools, gymnasiums, covered multi-sport halls, tennis courts, fitness and dance rooms...

\section{2) Underutilized infrastructure}

With regard to this item, the results of the survey allowed us to conclude that the access modalities of the students to the sports facilities of the University hardly allow their optimal exploitation. In this sense, the majority of the students questioned $(79 \%)$ attest that they have enormous difficulties in accessing the UAE's sports facilities, regardless of the institution to which they belong. While students from one school or faculty often have free access (without any prerequisites) to the sports facilities of their institution, it is very difficult for them to do the same at another institution belonging to the same university. This situation reflects the way in which institutions belonging to the same university, or even belonging to the same site, operate, characterized by a lack of pooling of resources and procedural flexibility that would allow students, especially from institutions that do not have land, to benefit from the opportunities offered. It should be remembered that the UAE is spread over four sites that are geographically distant from each other; Tetouan, Tangier, Martil and Larache. 
Consequently, the sports facilities are scattered over these four sites, which further complicates their mutual exploitation.

Finally, we have noted that the UAE's sports facilities are not used in the evenings, mornings or weekends (Saturdays and Sundays), and rarely in the afternoons.

This accentuates the decline in the rate of use of the sports areas and equipment. This observation makes the argument of the insufficiency of the sports infrastructure as a factor that hinders the elaboration of a sports project at the service of the students, encouraging them to practice sports.

\section{3) "Abandoned" infrastructures}

In another register, more than half (57\%) of the fields and playgrounds, sports equipment and materials, locker rooms, showers, and others are in a deplorable state. The causes of the deterioration of this sports infrastructure are many and varied. According to the interviewees, the aging of these facilities is the primary cause of their current state $(67 \%)$, given that the majority of sports facilities are as old as the institution where they are located (93\%). The origin of the degradation of these sports areas is also due, without any doubt, to the lack of regular maintenance of the sports grounds. $85 \%$ of the respondents affirm that the sports facilities of their institution have not been upgraded or restructured.

The absence of an improvement project (construction, extension, maintenance...) of the sports infrastructure among the decision makers (Presidents of the UAE and heads of institutions under the UAE) is justified in fine by the lack of financial means and the insufficiency of budget, by the importance given to certain projects considered as priority and urgent and especially by the high cost that requires the creation of new sport spaces or even their maintenance.

In addition, these facilities are often used by strangers to the university (e.g., the Faculty of Science and the Faculty of Arts). This was stated by students and the person in charge of sports in these two institutions.

It should be noted, on the other hand, that the increase of the university population constitutes an obstacle in the sense that it does not give rise to any accompanying measures on the infrastructural level. There is no development of sports facilities despite the plethora of students in the universities.

\section{4) Insufficient and defective equipment}

Some of the arguments put forward in the treatment of the "sports infrastructure" indicator also seem to be valid in demonstrating that the material means (balls, goals, sports accessories, didactic material...) remain so insufficient and lacking in quality to promote an attractive sports practice in an educational and secure framework. The results of the study show that PE teachers, sports managers and students rarely mention the material problem given the low rate of practice and sports activities scheduled annually. However, they do not hesitate to qualify it as a "serious problem" in the image of the infrastructure. During our survey, we had difficulty in identifying the sports equipment available to the UAE. For each institution, object of the census, we found ourselves faced with debris of sports equipment scattered over several corners of the institution. With little or no value, this equipment is considered by most of the actors concerned as worn out and unusable.

The material means also refer to the office equipment (computers, telephone, fax, Internet, office supplies...) necessary for the accomplishment of the administrative tasks and the management of the sports structures of the different institutions of the UAE.

In this sense, the survey shows that the offices of the local structures, when they exist (only five institutions have a service and a room dedicated to sports) do not have computer and office equipment, except for some where there is a combination of functions of the person in charge of student affairs and the person in charge of the sports service and social and cultural affairs: case of the faculty of arts. This allowed us to deduce that these structures are, in majority, neither functional nor operational. Bodies with no serious function become rather a burden for the institution and the University.

\section{B. Insufficient management and qualified human resources}

Quality sports activities and good sports management at the UAE undoubtedly require sufficient, specialized and qualified personnel. However, it appears from our survey that the university has only seven (7) staff members in charge of supervising 36163 students in sports. This represents a supervision rate of 5166 students per supervisor:

TABLE III. OVERALL USABLE SPORTS AREA BROKEN DOWN BY

\begin{tabular}{|c|c|c|c|c|}
\hline Institution & Number & Status & Qualification & Total \\
\hline ENS & 1 & Full timer & Not Specialized & \multirow{13}{*}{07} \\
\hline FLSH & 0 & --- & -- & \\
\hline FPT & 1 & Full timer & Specialized & \\
\hline FS & 1 & Full timer & Not Specialized & \\
\hline ENSAT & 0 & --- & --- & \\
\hline FST & 0 & --- & --- & \\
\hline ENSAT & 1 & Part timer & Not Specialized & \\
\hline ENCGT & 2 & Part timer & Specialized & \\
\hline FSJES & 0 & --- & --- & \\
\hline ISRFT & 0 & --- & -- & \\
\hline FPL & 0 & --- & --- & \\
\hline CUTE & 1 & Full timer & Specialized & \\
\hline CUTA & 0 & --- & --- & \\
\hline
\end{tabular}

However, our investigations have shown that the sports affairs departments of the UAE and the institutions that depend on it are managed, in the best of cases, by a single person, often charged with other tasks and 
responsibilities. In this sense, the general secretaries of faculties and schools of the UAE state that "in the absence of sufficient administrative staff, we find ourselves obliged to multiply the missions of each agent. Sports can be managed by the students themselves. We only intervene when necessary". However, the functions of animation, training and sports supervision, management of structures, elaboration of local sports development projects, annual and biannual programming of physical and sports activities.... cannot be carried out properly by a single person in charge (more than $60 \%$ of the cases) or by the students themselves (a little less than 40\%). However, the accomplishment of these functions should rather be the responsibility of specialist-actors [6], strictly mandated for this mission and having the means corresponding to the importance of their activities.

Thus, the UAE sports office, based at the Presidency, has only one person who is responsible for the administrative and sports tasks that are confusingly assigned to it. This body, which is supposed to be responsible for the strategic and organizational policy of sport at the University, is deprived of sufficient human resources to properly accomplish its role.

On a parallel register, the Physical and Sports Activities are provided, in the UAE universities, by nonspecialists, who do not have a specific training in the field of sports and its management [7]. This poses a problem of qualified resources, a sine-qua-non condition for success in the roles of facilitator, teacher and manager of the sports structure.

Finally, our investigations have allowed us to reveal that, contrary to what was happening a few years ago, students are less and less involved in the tasks of animation and sports management of their peers. Almost half of those questioned (62\% of those in charge of sports affairs in the UAE-Tetouan institutions) testify that "it has become inappropriate to make one or more students responsible for leading, managing or coaching their fellow students. They are less serious and less enterprising". They add that "it has also become more difficult to ensure the participation of the best elements in the various competitions organized, in principle, for their benefit".

In view of all these considerations, we were able to conclude that sufficient and qualified human resources in the field of sport in the UAE are definitely below the standards required for the normal functioning of this sector [8]. This situation could therefore be at the root of the current state of sport in the UAE.

\section{Very insufficient financial resources}

Recalling that the revenues of the league and the sports associations of the UAE institutions are composed of registration fees, membership fees, subsidies allocated by the State and local authorities and others [9]. When we learn that the said league and associations have not been functional for at least four (4) years, we can easily deduce that the funds collected on behalf of these two bodies are reduced to nothing.

In relation to this reality, the interviewees explain: "This situation is due to the suspension of the university championship of team and individual sports".

The UAE is a public institution with legal personality and financial autonomy. In financial terms, the institutions under its authority are largely, if not entirely, dependent on it [10]. As a result, the University's contribution remains the main source of funding for sports-related activities within these institutions. On the other hand, there is an almost total absence of sponsoring actions, very few strategic or specific partnership projects aimed at financing sports actions and initiatives.

Following the analysis of the documents that we were able to consult [11]. (at the level of the presidency as well as at the level of the faculties and schools), we were able to note a total absence of identifiable financing on the program "Student Life" or other clearly intended for the sports sector.

An examination of the financial reports and budget breakdowns, whether in terms of strategic presentation or justification to the first dirham, shows nothing except a chapter without a substantial budget for social, cultural and sports activities. A global but not earmarked funding is reserved for campuses, health, sports, cultural and social activities. In fact, for all sectors of intervention such as the upgrading of existing sports infrastructure, access to sports services for all, and even the purchase of light sports equipment, the budgets are not quantified and therefore not earmarked. This gives managers more or less flexibility to direct the budget towards the financing of sectors and activities that they deem to be of higher priority, more interesting or more urgent.

However, if the President (and his staff [12].) never ceases to express his desire to develop sports at the University, he has never tried to act and release the necessary means. This is ultimately to discredit the sport in the UAE community. The President remains consistent with the clear position she expressed at the beginning of our interview with him: "Sport is not a priority in my project [13]. I am fully aware of its importance in the training curriculum of our students, but faced with more urgent challenges, it can only wait". The result is a sports budget that is equal to the importance given to it.

Moreover, the statements of the various heads of UAE institutions corroborate the President's words. They all affirmed that the financial means they currently have at their disposal cannot meet their sporting ambitions. Paradoxically, and in the absence of formalized projects aimed at promoting sport in these institutions, we had difficulty identifying the nature of such ambitions. The majority of UAE institutions operate with an estimated annual operating budget of one hundred thousand (100.000) MAD. Two institutions preferred not to provide a figure. 
Also, the budget allocated to sports at the two university cities Tangier and Tetouan [14], also remains insufficient and does not cover all needs. The situation is more deplorable in the city of Tangier given the total absence of infrastructure, human and material resources dedicated to sports activities. In this context, it becomes difficult to engage the responsible in budgetary matters in the field of sport.

Still in the same line of ideas, being free services that the State offers to students, the latter are exempted from any financial charge to benefit from the teachings and sports activities programmed in the schools or faculties. The principle of free access is "clumsily interpreted by several actors [15]". This disproportionate interpretation "makes the budget of the faculty and the University lose an important financial contribution which would allow to launch considerable sports projects", explain the head of a university institution. The latter adds that "this same gratuity, obviously with other factors, also makes the value of sports programs lose in the eyes of our students. It harms the natural motivation of young people to consume the sports product". In this sense, more than two thirds $(2 / 3)$ of the leaders are suspicious of possible strategies to impose fees on students. The pretexts put forward vary between the absence of a legal framework that regulates this operation and the socio-economic situation of most UAE students, who are mostly from middle or underprivileged economic classes.

Can university sport really move forward? In all circumstances, the means made available to it do not encourage or tend towards the expected influence of this important sector of sport at the UAE. Worse, it does not seem to escape other difficulties that we will show in what follows.

The financing of university sports remains precarious. The sustainability of funding remains subject to the vagaries and priorities of each academic institution.

\section{Lack of sports governance in the UAE}

The Moroccan state is pursuing a policy of decentralization and administrative deconcentration: a decisive choice, an irreversible strategy and an urgent responsibility. Lever $\mathrm{xv}$ of the National Charter of Education and Training established decentralization and deconcentration in the education and training sector. "It is necessary to adapt education and training to regional and local needs. It is also important to simplify, streamline and accelerate the procedures for managing the growing number of infrastructures and the increasing number of learners and supervisors in the education-training sector. Freeing up constructive initiatives while clearly situating responsibilities" [16].

If the organization of the university system reflects this orientation of decentralization and deconcentration" [17], it also engages the responsibility of the university for the management of university sports, a component of the system that is imposed by necessity. The UAE becomes accountable to the students, to the administration and to the political and social forces as soon as it puts, or does not put, in place the necessary conditions for the practice of a constitutional and legal right recognized to every university student: the right to the supervised practice of sports activities.

The survey we conducted reveals that in the area of university sports and its development, the institutional actors (all constituents of the UAE) are experiencing enormous difficulties related to the definition of a future vision, the mobilization of resources and skills and the continuous evaluation of performance.

\section{1) The regulatory framework needs to be reviewed}

Like other Moroccan universities, sport at the UAE faces difficulties from a regulatory point of view. The absence of links ensuring continuity between school sports, university sports and possibly civil sports is an obstacle to its development. It even calls into question the orientations assigned to this field of sports practice.

The main legal texts regulating the practice of sport and PSE in Moroccan universities can be summarized in three laws and one reference text. In addition to the National Charter of Education and Training, it is the text of law $\mathrm{n}^{\circ}$ 30-09 and its decree of application, law $n^{\circ} 01-00$ relating to the organization of the higher education and the law $n^{\circ}$ 81-00 relating to the National Office of the University, Social and Cultural Works which constitute the base as regards organization and operation of the system of the physical activities and university sports. However, and with the exception of the text of law 30-09 relating to physical education and sports, all the other texts do not confer the obligatory character to the teaching and the practice of the EPS and the sport in the university.

The interviews we conducted for this study show that the heads of the various UAE institutions are still not aware of this fact. Let's sign: the law dates from 2009, and it's implementing decree from 2010. They continue that they have not had any instructions or guidance from their superiors or supervisors about the imperative inclusion of PES as a subject (module element) in the training and teaching curricula in the university study cycles.

The President of the UAE specifies in this sense that such a legal provision will find enormous difficulties in its operationalization. If the university will be called upon to translate this principle into reality, it is only bound by an obligation of means. And as long as the available resources are limited in the face of the enormous challenges to be won, sport at the university is not only condemned to remain in the state it is in but risks no longer being included in the university or even parauniversity offer.

This senior official of the UAE is not opposed to initiatives that would come from teachers-researchers, 
members of the University Council, to include EPS in university programs like languages and new information technology and communication (NTIC). But the tone of the pessimist envelops his words of the moment where relativizes ipso facto the scope of his proposal. In this sense, he said "the teachers of the UAE put pressure against the practice of generalizing module elements related to languages and ICTs under the pretext of absorbing a large volume of time that could be beneficial to other specialty subjects to be included in the programs of the channels". The head of the UAE reinforces his words by adding that to generalize the EPS on the cycles of teaching, would require colossal investments in infrastructure and sports supervision to cover all the demand. The UAE remains financially unable to engage such projects, at least for the moment and also for the near future.

However, financial difficulties have not been a blocking factor to some isolated initiatives in this direction. Two institutions with regulated access" [18] are programming a module element for sports and cultural development for the benefit of their students in the Engineering, DUT and Bachelor cycles. Aware of the importance of sports practice in the complete training of the student, the heads of institutions and coordinators of the courses have opted for this choice and they have launched into its realization with "the means at their disposal, while trying to improve their offers from one year to another" [19]. These decisions seem to respond less to the concern of reacting to the recommendations of the law 30-09 concerning the obligation of the EPS in the higher education, but rather translate the increasing interest that the designers of these courses grant to the physical and sports activities in the supervision of the young people and to their personal development and future professional blooming.

In addition, we note that school sport and university sport are under the supervision of two separate departments: the Directorate for the Promotion of School Sport and the Royal Moroccan Federation of School Sport for the first and the National Office of University, Social and Cultural Works and the Royal Moroccan Federation of University Sport for the second. It appears from our interviews that this separation constitutes today a challenge [20]. Its compartmentalized organization according to the different levels of education, gives an obvious impression of scattering, even of division, and therefore of waste of means.

Obviously, it is difficult to elaborate coherent and successful projects while ensuring their follow-up and their evaluation, as it is painful to accompany the students' passage between the cycles of primary, secondary and higher education in the absence of sports structures which share the same vision of things and elaborate together and in a coordinated and concerted way strategies and clear and apparent action plans. In fact, PE teachers and sports managers of the different EUs are demanding a single structure that manages both school and university sports. Such an arrangement, as well as ensuring greater visibility and unity of the structure responsible for it, would solve in the process a number of problems related to infrastructure and material means and qualified human resources through their mutualization.

\section{2) Lack of strategic direction}

The treatment of the collected data allowed us to conclude that the leaders of the UAE do not identify with a vision, a mission and clear strategic orientations as regards the development of the sport/physical education system. Indeed, the vision of the majority of those consulted (twelve out of fifteen) is not congruent with the recommendations of the national charter of education and training, nor with the provisions of the law 30-09 [21], nor with the project $n^{\circ} 6$ of the plan of the Ministry of Higher Education [22], nor with the salient features of the 2020 vision of Moroccan sport [23] such as "Anchor the practice of sport and its values in the daily life of everyone" and "Make Morocco a land of sport and a melting pot of champions".

It appears from our interviews with these officials that the way they represent university sports no longer rhymes with the vision and orientations of the State regarding sports. Confusing vision, mission and objectives, $75 \%$ of these officials give more importance to the operational register than to the global strategic framework when they formulate their wishes concerning university sports and its development.

The creation at the ENS of the UAE of a professional degree in Management and Administration of Sport (M.A.S) could have been understood as an internal strategy of the university to translate the national vision of sport, broken down into a series of objectives including "Boosting the training channels for sports professions". Unfortunately, it was enough to change the person in charge (President of the UAE) for the motivation to decrease with regard to this course, to question its domiciliation and to speak already about a possible nonrenewal for a second period, even before proceeding to the objective evaluation of this course. This suggests that the initial choice was not strategic. This is a new element that corroborates what we have said about the lack of strategy in the management of sport at the UAE.

Moreover, all the heads of the institutions reduce their sports mission around a humanistic, social and playful orientation, i.e., a sport that offers a space and means to energize student life in the residence halls and during free time. Therefore, the concept of sports performance, obtaining medals, organizing sports events and competitiveness of UAE teams, are very rarely advanced.

We can conclude from the above that the President, Directors and Deans of the different UAE institutions show a more or less accentuated confusion between the vision, mission and objectives of university sports. The absence of a strategy for the development of sport at the 
UAE leaves room for humanistic reflections, thus neglecting an equally important aspect: elite university sport where the values of selection, competition, performance and medals reign...

\section{3) Poor organization}

The clear statements of some members of the commission in charge of social, cultural and sports affairs (CASCS) of the UAE suggest that this structure has no strategy, no vision and no means to undertake actions for the benefit of sport in the UAE.

These same members claim first of all that their election/designation/choice to belong to this commission has only a formal basis. In other words, the members of this management body are not selected on the basis of intelligible criteria such as the motivation of the persons (professors and others), their experience in the field or by considering their possible competences in the management and animation of social, cultural or sports activities.

Secondly, they note that, in contrast to social and cultural activities, the issue of sport at the UAE is very rarely raised at meetings of this committee. One of the interviewees openly states that "we have never been called upon to reflect or act on the cause of university sport". He adds that no initiative has been taken by any member of the committee in this sense.

Finally, the total lack of coordination between CBSI and the sport service at the UAE, an administrative structure, raises the serious question of governance of sport in the university. The person in charge of this service affirms that with the arrival of the new president, many things have changed:

- The sport service is less and less functional ;

- The means allocated to this service are constantly decreasing ;

- Difficulties in communicating with superiors ;

- Rupture between the two entities in charge of sport at the level of the presidency (the administrative manager is never invited to the SSCC meetings) ;

- When the UAE makes a report on its activities, it does not ask the sports department to do its own...

\section{4) Failure to evaluate the PE/sport system at UAE}

Improving the governance of $\mathrm{PE}$ and sports activities at the UAE must involve the continuous evaluation of this system as part of the university's education and training provision. However, neither the university nor the institutions under its auspices carry out serious and regular evaluation of the sector's performance. In this sense, the reports, accounts and balance sheets that we have been able to examine do not mention anything in this regard, except for certain sports activities (tournaments, meetings, etc.) scheduled during the academic year.

The examination of the evaluation report of Abdelmalek Essaâdi University in 2010 allows us to make two important remarks:

a. In terms of sports, the report only mentions generalities such as the absence of an integrated cultural and sports policy, insufficient budget...

b. Sport is closely linked to, if not confused with, social and cultural issues.

\section{5) Poorly committed and unmotivated actors}

If the UAE guarantees students access to supervised university sports, today, these same university students show little commitment and/or little motivation. Students do not demand such a right when it is lacking.

\section{1) Physical education teachers engagement :}

The involvement of physical education and sports teachers in university sports activities leaves much to be desired. Although they have paid hours in their salaries, it appears from our interviews that some teachers, instead of fulfilling their duty to ensure sports supervision, spend their time doing black market work by engaging in other activities in the private sector. Worse, most of the boycotters of school sports competitions abandon their schools and go to private schools where they are still paid. This poses a problem of ethics and loyalty on the part of these teachers. These considerations show that these agents are not thinking of serving but rather of serving themselves. Instead of imagining solutions to revitalize university sports, they are more concerned with their personal interests by knowingly or unknowingly devaluing their profession.

\section{2) Unmotivated students :}

From our interviews with administrative officials in the university sector, it appears that UAE students and their parents are less and less motivated to take part in sports activities.

Among students, this lack of motivation seems to be explained by the fact that there is no follow-up for the young talents detected, nor for the trainees trained, nor rewards that could motivate them further. Also, there is no recognition of the commitment of students by their institutions. In other words, no support measures are given to student athletes (Lack of recognition, lack of external motivation: pocket money, internship, scholarships, etc.).

As for the parents, they do not seem to encourage the practice of sports at school given the lack of means as well as all these problems mentioned above. This is why parents refuse to allow their children to engage in activities other than their studies. This is more noticeable in schools with regulated access, where the priority for parents is their children's schooling, especially since they 
invest a lot of money in their success. This is another factor limiting the development of university sports at the UAE.

However, difficulties related to resources and the lack of consideration for athletic requirements in relation to academic ones seem to be the main causes of this lack of motivation.

\section{6) Living conditions of students}

The other factor that constitutes a difficulty for the promotion of sports at the UAE is the living conditions of the students.

The lack of canteens, poverty, distance from home, and the introduction of the "day-continuous" system, in addition to transportation problems, constitute an obstacle to the development of sports at the UAE. Students are not in optimal conditions to train with their teams. They are more concerned with their physical and intellectual integrity, which consists in going home, recuperating and putting themselves in the process of acquiring knowledge.

The university sport seems to know deficits at all levels: human, material, financial, institutional, organizational, ethical and motivational. In addition, we have an insufficiency of activities, an absence of commitment of the physical education teachers responsible for the sports animation, a disinterest of the parents, finally an inadequacy and an incoherence of the texts compared to the practice of the sport today.

As such, and in view of all the reflections made in this sector, the university sport has failed in its missions, hence the need to revisit the texts that organize it. Thus, we will, at the end of this diagnosis, propose ways and solutions for the problems that this important sector of the sporting practice faces in Morocco.

\section{CONClusion}

Sport is a reality in the Abdelmalek Essaâdi University. However, it is absent from the developmental project of the UAE and its institutions. Sport and PES do not occupy a very significant place in the training programmes and in the academic life of students in most of the UAE institutions. Physical and sports activities are not widely practiced, despite the importance of PE and sports activities in the training and personal and social development of students in the different cycles of higher education, whatever their field of study.

In the context of the UAE-Tetouan, this "crisis" situation is explained, among other things, by the lack of resources, both human, material and financial, necessary for the supervised, generalized and safe practice of Physical and Sports Activities. In this sense, this reflection has analyzed the explanatory factors of such a situation and verified whether the factors related to sports infrastructure and equipment, governance and financial and human means that are responsible for the current deficient state of national sport, are also responsible for sport in the UAE.
In the end, we can conclude that Moroccan national and university sport, on the one hand, and sport at the UAE-Tetouan, on the other, suffer more or less equally from a lack of resources and a lack of modern managerial practices in the management of institutional or associative structures in charge of sport in the UAE's institutions. Problems related to infrastructure and equipment, human and financial resources, managerial skills and institutional structures are indeed major factors blocking the development of the Sport/EPS system in this university. In general, there is a significant gap between the intentions expressed in favor of the place that sport should occupy in the training and leisure programmes of UAE students, and what is implemented to concretize these aspirations.

\section{REFERENCES}

[1] Law 30-09 on physical education and sports, chapter one "School and university physical and sports activities", art. 2nd, 2009.

[2] Royal letter from His Majesty King Mohamed VI to the National Sports Conferences, 2008.

[3] In this article, we deal only with the sources of dysfunction in sport in the UAE. We will devote the next article to a proposal for its development.

[4] National Strategy for the Development of Sport, Ministry of Youth and Sport, 2008.

[5] Belfekih C., (2008). State policy on women's sports in Tunisia. Master's thesis in administration and management of the spot, ISSEP of Tunis.

[6] Gharib A., (2008). Sport and the crisis of governance. In New Sports Governance in Morocco. Under the direction of Harakat M., Centre International des Etudes Stratégiques et de Gouvernance Global, p. 15.

[7] Contrary to what is claimed by the heads of schools in relation to the competence of their staff in charge of sport, some of the latter do not hesitate to openly deny this reality; $70 \%$ of this category of actors declare that they have not received any initial training leading to a qualification to carry out the function of manager, educator or sports leader... "We were forced by the administration to take charge of this sports service... ", some of them explicitly stated.

[8] Andaki I., (2012). Human resources issues in sport in Morocco. In master's thesis, FSE, Rabat, p. 145.

[9] Some private partners participate punctually and to a derisory extent in the financing of certain UAE sports activities.

[10] The case of three out of eleven institutions that have no other source of funding.

[11] Only two institutions made their detailed financial reports available to us. The presidency and the rest of the institutions only provided us with summaries that lacked usable data.

[12] In particular the vice-president in charge of pedagogical, social, cultural and sports affairs.

[13] Ben Abdessalam M. \& Hasnaoui K., (2012). University sport in Morocco. Dissertation presented for the master's degree in management and engineering of sports organizations, Med VSouissi University, Rabat.

[14] It should be noted that the two directors interviewed did not give us any details concerning this budget.

[15] Dean of the Faculty of Legal, Economic and Social Sciences, UAE, Tangier.

[16] National Education and Training Charter, Moroccan Ministry of national education, 1999 
[17] The Moroccan University, an institution which often marks a regional territory, enjoys a triple autonomy: financial, administrative and legal.

[18] National School of Commerce and Management-Tangier and Higher School of Education Tetouan.

[19] Words of the Director of National School of Commerce and Management-Tangier.

[20] Two knowledgeable PE teachers spoke out on this issue.

[21] Law 30-09 on physical education and sports, Op.cit, preamble.

[22] Project-work plan of the Ministry of Higher Education, Scientific Research and Executive Training 2013-2016.

[23] Royal recommendations formulated during the national conference on sport in Morocco, Skhirat 2008. 